\title{
From Germany
}

\author{
Gerhard L Bach
}

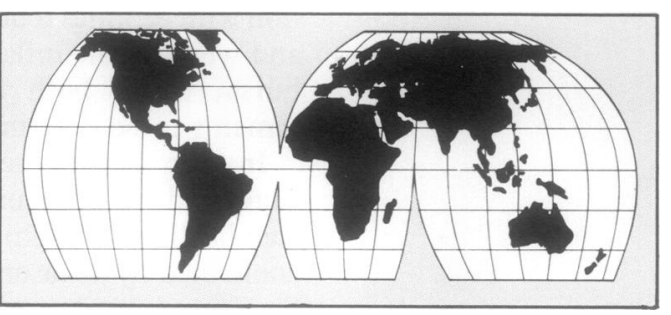

During 1991 German rheumatologists were active in basic research and in attempting to improve the rheumatological curriculum and care of patients with rheumatic diseases. A major part of their effort was directed towards the five 'new states' of the former German Democratic Republic. The Bonn government did not follow the recommendations made by the German Society of Rheumatology to support the East German 'dispensaires'-units for the diagnosis and treatment of patients with rheumatic conditions. These dispensaires were very successful in treating patients, but as in the case of the unit for the city and rural district of Schwerin, which was closed down after 27 years, they proved unprofitable, and, in Schwerin a governmental insurance administration (Landesversicherungsanstalt) took over the rooms for administrative purposes!

Despite the closure of the dispensaires a survey by Professor Keitel, VogelsangGommern, showed that there was no shortage of rheumatologists or internists with rheumatological experience in these new states. Professor Haentzschel, Leipzig, confirmed that the care of patients with rheumatic ailments might even have improved since former clinic specialists settled in private practice.

In the united Germany numerous seminars and congresses took place as in previous years, partly in union with the Austrian and Swiss societies. Of course, there was a demand for medical education and exchange of information in the East German states. To promote rheumatology the Bonn Ministry of Health intends to fund 'centres of rheumatology', in which the universities will have a leading role. Although the intention to promote rheumatology is commendable, one asks if this approach might not be improved: the role of existing rheumatology clinics should be taken more into consideration as most German universities have no established rheumatology departments, and why not create chairs for rheumatology?

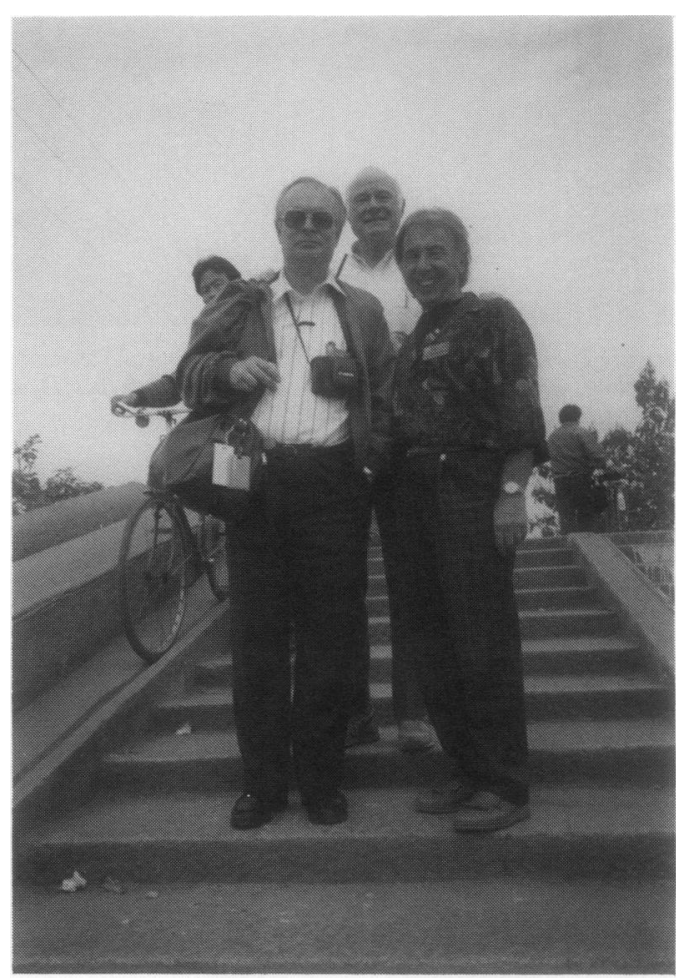

Left to right: Gerhard Bach, Daniel McCarty, George Vetter.

Professor Haentzschel's work on rheumatoid arthritis and scleroderma was supported by a governmental grant. Professor MüllerFassbender, Bad Abbach, completed a large study of sulphasalazine in the treatment of rheumatoid arthritis and other rheumatic diseases. In meticulous trials Professor Lemmel, Baden Baden, found interferon gamma useful in the treatment of rheumatoid arthritis. In Wiesbaden Dr Bandilla completed a study using a commercially available mixture of enzymes in rheumatoid arthritis. This carefully planned trial found no difference between the drug under investigation and placebo.

Professor Zeitler, Hannover, has been named as representative for the EULAR committee program 'Rheumatologists in training'. Professor Keitel has been commissioned by the German Society of Rheumatology to assure quality in rheumatology. Professor Bach, Bensheim, was an invited guest professor in Alexandria, Egypt. Dr Vetter and Professor Bach joined the rheumatology delegation 1991 to the People's Republic of China, which was led by Dr McCarty from the University of Wisconsin.
Klinik Auerbach 6140 Bensheim 3 Germany 